Proceedings of the

Combustion Institute

\title{
The growth of PAHs and soot in the post-flame region
}

\author{
Peng Liu*, Zepeng Li, William L. Roberts \\ Clean Combustion Research Center, King Abdullah University of Science and Technology (KAUST), Thuwal 23955-6900, \\ Saudi Arabia
}

Received 28 November 2017; accepted 22 May 2018

Available online xxx

\begin{abstract}
The PAHs- $\mathrm{C}_{2} \mathrm{H}_{2}$ pathway (PAHs $+\mathrm{C}_{2} \mathrm{H}_{2} \rightarrow$ intermediate $\rightarrow$ product $+\mathrm{H}_{2}$ ) has been shown, in theory, to be the important contributor to the growth of polycyclic aromatic hydrocarbons (PAHs) and soot in the post-flame region where $\mathrm{H}$ atoms are rare. Calculations of the potential energy surface (PES) using the DFT B3LYP 6-311 + G(d,p) method, and the reaction rate coefficients using the RRKM theory, reveal that armchair and bridge surface sites share similar kinetic characteristics, and are more likely to be the targets of $\mathrm{C}_{2} \mathrm{H}_{2}$ molecules in flames compared to zig-zag and 5-membered ring surface sites. Results show that the energy barrier of a $2-\mathrm{H}$ elimination reaction $(14-23.8 \mathrm{kcal} / \mathrm{mol})$ is much lower than that of a $1-\mathrm{H}$ elimination (typically $30-40 \mathrm{kcal} / \mathrm{mol}$ ) for some molecules. The formation of pyrene from phenanthrene via HACA $\left(\mathrm{PAHs}+\mathrm{H} \rightarrow\right.$ PAHs radical $\left(+\mathrm{C}_{2} \mathrm{H}_{2}\right) \rightarrow$ intermediate $\rightarrow$ product $+\mathrm{H}$ ) and $\mathrm{PAHs}-\mathrm{C}_{2} \mathrm{H}_{2}$ pathways is investigated using a closed homogeneous zero-dimensional reactor with combustion parameters abstracted from the premixed stagnation $\mathrm{C}_{2} \mathrm{H}_{4} / \mathrm{O}_{2} / \mathrm{Ar}$ sooting flame. Results show that the HACA pathway is the dominant pathway for the formation of PAHs and soot surface growth in the main-flame region where $\mathrm{H}$ atoms are abundant, but that the PAHs- $\mathrm{C}_{2} \mathrm{H}_{2}$ pathway is the preferred pathway in the post-flame region. Our study also suggests that the soot nucleation involving a chemical coalescence of moderate-sized PAHs into a crosslinked three-dimensional structure via the addition reactions of PAHs and PAH radicals in the main-flame region should be considered for inclusion in any soot modeling.

C) 2018 The Combustion Institute. Published by Elsevier Inc. All rights reserved.
\end{abstract}

Keywords: PAHs; Soot; Nucleation; Surface growth; DFT

\section{Introduction}

Driven by the need to continually improve the design and performance of clean combustion engines, our understanding of polycyclic aromatic hydrocarbons (PAHs) and soot formation has evolved

\footnotetext{
* Corresponding author.

E-mail addresses: peng.liu.1@kaust.edu.sa, thereisadream@126.com (P. Liu).
}

from phenomenological observation to quantitative description over the last two decades, especially in $\mathrm{C}_{2} \mathrm{H}_{4}$ flames [1-4]. It is well accepted that benzene plays an important role in the formation of PAHs and soot, and that it is formed mainly by the addition reaction $\mathrm{C}_{2} \mathrm{H}_{x}+\mathrm{C}_{4} \mathrm{H}_{x}$, the recombination reaction of two $\mathrm{C}_{3} \mathrm{H}_{3}$ radicals, and the cyclization reaction of $\mathrm{C}_{6} \mathrm{H}_{x}$ [5-8]. The formation of PAHs starting from benzene has been modeled by the widely used hydrogen-abstraction - carbonaddition (HACA) pathway, which was originally 
proposed by Frenklach and co-workers [7, 9]. However, the HACA pathway is not strong enough to explain the fact that the formation of PAHs and soot still occurs in the post-flame region where the concentration of $\mathrm{H}$ atoms is very low [3].

The electronic, photonic, transport, spin and chemical reactivity properties of PAHs have sparked intense interest in materials science [10,11]. This is because PAHs can be used as model molecules for nanographenes [12], which are promising candidates for key applications of non-linear optics [13]. The theoretical study by Nagai et al. [14] and You et al. [15] showed that the PAHs have significant di-radical or multi-radical characteristics, and that the edge of PAHs is the main active moiety via analysis of molecular orbital theory. Therefore, the addition of active small molecules to the edge of PAHs may happen in flames. Among active small molecules, $\mathrm{C}_{2} \mathrm{H}_{2}$ molecule should be the priority object due to the triple bond and relative high concentration in the whole flame region. Additionally, a study by Kislov et al. showed that the addition of $\mathrm{C}_{2} \mathrm{H}_{2}$ to biphenyl led to the formation of phenanthrene without the presence of $\mathrm{H}$ atoms [16], and suggested that the growth of PAHs and soot without the assistance from $\mathrm{H}$ atoms at high temperature is possible. This provides a potential pathway accounting for PAHs and soot growth in the post-flame region where the temperature is higher than $1500 \mathrm{~K}$. However, the probability for $\mathrm{C}_{2} \mathrm{H}_{2}$ addition to different surface site of PAHs (or soot) needs further investigation, as the oxidation rate of PAHs is very sensitive to the type of surface site targeted by oxygen atoms [17,18]. Additionally, the competitiveness of the PAHs- $\mathrm{C}_{2} \mathrm{H}_{2}$ pathway $\left(\mathrm{PAHs}+\mathrm{C}_{2} \mathrm{H}_{2} \rightarrow\right.$ intermediate $\rightarrow$ product $+\mathrm{H}_{2}$ ) in sooting flame needs further discussion.

Here, the sensitivity of the PAHs $+\mathrm{C}_{2} \mathrm{H}_{2}$ pathway towards the type of surface site exhibited by PAHs is closely examined. Particular attention is paid to the zig-zag (naphthalene), armchair (phenanthrene), 5-membered ring (acenaphthylene), and bridge (biphenyl) surface sites. The bridge surface sites have received less attention in previous studies, yet they may be very abundant in transportation fuel flames. Indeed, mass spectrometric data reveal that the phenyl radical addition reaction (like phenyl + phenyl $\rightarrow$ biphenyl) should be the main growth pathway of PAHs instead of the acetylene addition reaction in benzene pyrolysis [19]. To extend the kinetic parameter of the PAHs $+\mathrm{C}_{2} \mathrm{H}_{2}$ pathway from PAHs to soot, the size effect of PAHs on the PAHs $+\mathrm{C}_{2} \mathrm{H}_{2}$ pathway is also examined.

The PES and reaction rate coefficients of the $\mathrm{PAH}+\mathrm{C}_{2} \mathrm{H}_{2}$ pathway using both the density functional theory (DFT) and the Rice - Ramsperger - Kassel-Marcus (RRKM) theory are investigated. Subsequently, the forma- tion of pyrene with the $\mathrm{PAH}+\mathrm{C}_{2} \mathrm{H}_{2}$ pathway first and then with the HACA pathway, both under $\mathrm{C}_{2} \mathrm{H}_{4}$ sooting flame conditions, is discussed. Finally, we evaluate the potential of a mechanism for soot nucleation and surface growth considering the PAHs $+\mathrm{C}_{2} \mathrm{H}_{2}$ pathway.

\section{Calculation details}

In this study, the optimization of molecule structures and vibrational frequency calculations were carried out using the DFT B3LYP 6$311+G(d, p)$ method $[20,21]$. A factor of 0.967 is applied to correct the vibrational frequencies. We further refine the PES of naphthalene $+\mathrm{C}_{2} \mathrm{H}_{2}$ and biphenyl $+\mathrm{C}_{2} \mathrm{H}_{2}$ reactions at the CBS-QB3 level, in order to estimate the precision of the energy value obtained with the DFT method. The application of the CBS-QB3 method to other PAHs is limited by its memory requirement; for example, $300 \mathrm{~GB}$ memory is not enough to store the integrals file of phenanthrene. Intrinsic reaction coordinate (IRC) calculations are performed to ensure that the transition state is connected to the corresponding reactant and product. The Gaussian 09 program package is selected for all quantum chemistry calculations [22].

We evaluate the rate coefficients of unimolecular thermal decomposition reactions based on the RRKM theory by solving the master equation using the MultiWell suite of codes (MultiWell2016.2) [23-25]. The rate coefficients of biomolecular reactions are derived from the corresponding unimolecular reaction rates and equilibrium constants. Brevity, the pressure is set as $1 \mathrm{~atm}$ in MultiWell suite and the exponential-down model with $\left\langle\Delta \mathrm{E}_{\text {down }}\right\rangle=260 \mathrm{~cm}^{-1}$ was selected to describe the collisional energy transfer. The argon was used as the bath gas collider with Lennard-Jones parameters $\sigma$ and $\varepsilon / \mathrm{kB}$ equaling to $3.47 \AA$ and $114 \mathrm{~K}$, respectively. More details on how we evaluate the rate coefficients can be found in our previous studies $[5,17]$.

\section{Results and discussion}

\subsection{Potential energy surface}

The chemical species are named according to the type of surface site $\mathrm{C}_{2} \mathrm{H}_{2}$ molecule targets. $\mathrm{S}$, $\mathrm{S} 2, \mathrm{~S} 3$ and $\mathrm{S} 4$ represent the PAHs- $\mathrm{C}_{2} \mathrm{H}_{2}$ pathway occurred on the armchair (Fig. 1a and b), bridge (Fig. 1c and d), zig-zag (Fig.S1 e and f) and 5membered ring (Fig.S1 $\mathrm{g}$ and h) surface sites of PAHs, respectively. The PAHs- $\mathrm{C}_{2} \mathrm{H}_{2}$ pathway comprises two elementary reaction steps: one is the addition of $\mathrm{C}_{2} \mathrm{H}_{2}$, and the other is the release of $\mathrm{H}_{2}$, as presented in Fig. 1. The addition of $\mathrm{C}_{2} \mathrm{H}_{2}$ of the PAHs- $\mathrm{C}_{2} \mathrm{H}_{2}$ pathway is highly sensitive to the 

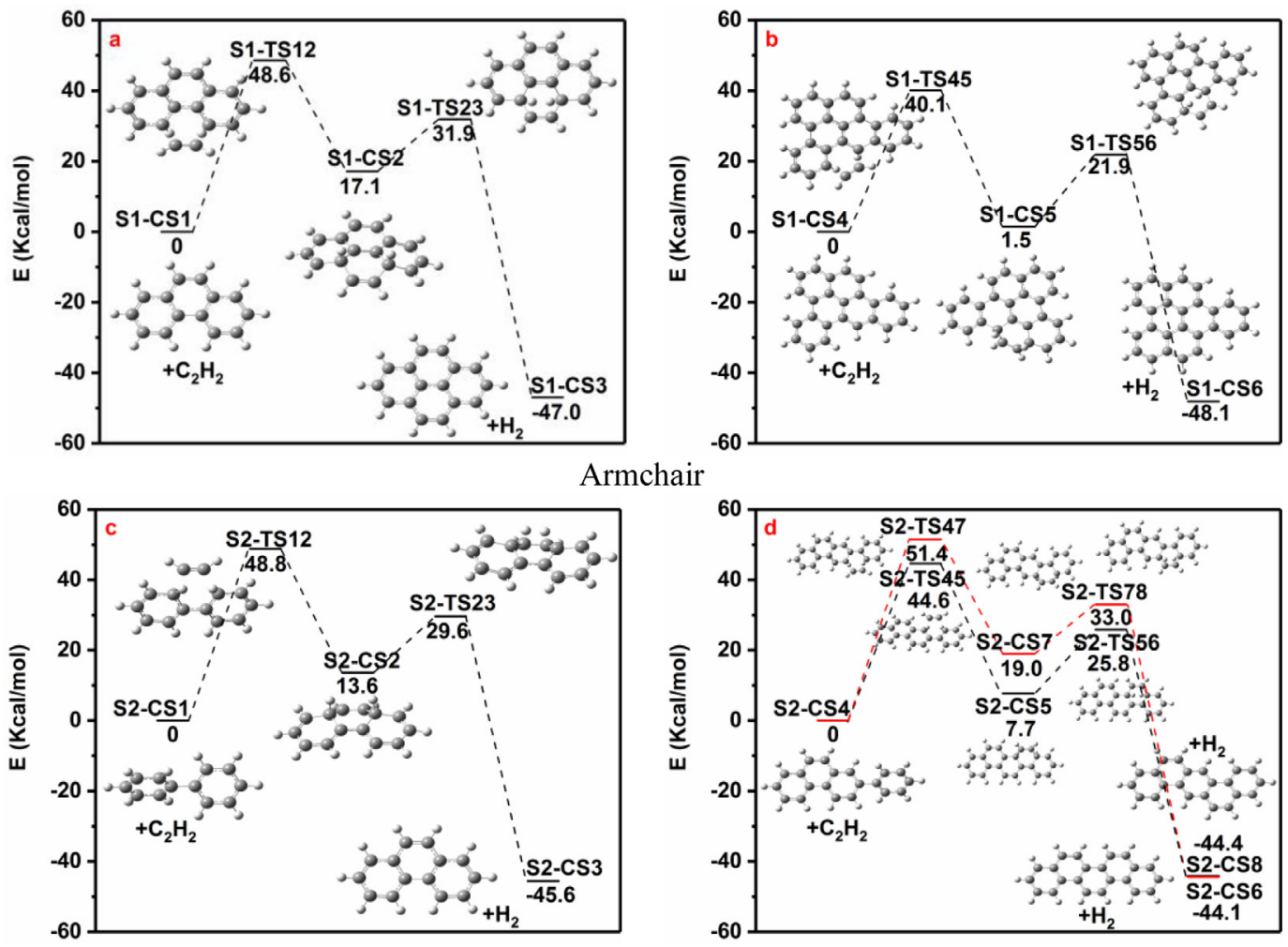

Bridge

Fig. 1. The potential energy surface for PAH- $\mathrm{C}_{2} \mathrm{H}_{2}$ pathway; the energies are calculated at B3LYP 6-311 + G(d,p) level.

type of surface site. It was found that the energy barrier of $\mathrm{C}_{2} \mathrm{H}_{2}$ addition to the zig-zag (naphthalene) and 5-membered ring (acenaphthylene) is 72.0 and $68.6 \mathrm{kcal} / \mathrm{mol}$, which is higher than that to the armchair (phenanthrene, $48.6 \mathrm{kcal} / \mathrm{mol}$ ) and bridge (biphenyl, $48.8 \mathrm{kcal} / \mathrm{mol}$ ) by at least $20 \mathrm{kcal} / \mathrm{mol}$, as shown in Fig.S1. This suggests that the armchair and bridge surface site are the priority target for the $\mathrm{C}_{2} \mathrm{H}_{2}$ molecule, compared with the zig-zag surface site and 5-membered ring surface site. For brevity, the detail of PAHs- $\mathrm{C}_{2} \mathrm{H}_{2}$ pathway occurred on zig-zag and 5-membered ring surface site is moved to the Fig.S1 of the supplementary material. The energy barrier of the 2-H elimination reaction $\left(\mathrm{S} 1-\mathrm{CS} 2 \rightarrow \mathrm{S} 1-\mathrm{CS} 3+\mathrm{H}_{2}\right)$ is as low as $14.8 \mathrm{kcal} / \mathrm{mol}$, which is much lower than the value $(92.3 \mathrm{kcal} / \mathrm{mol})$ in our previous study [8] for a similar 2-H elimination reaction, and even lower than that of $1-\mathrm{H}$ elimination reaction (typically 30 $40 \mathrm{kcal} / \mathrm{mol}$ ) [5]. The elementary reaction features of the PAHs- $\mathrm{C}_{2} \mathrm{H}_{2}$ pathway are almost insensitive to the size of PAHs, but the energy barrier for the addition of $\mathrm{C}_{2} \mathrm{H}_{2}$ slightly decreases for larger PAHs. For example, the energy barriers for the reactions $\mathrm{S} 1-\mathrm{CS} 4+\mathrm{C}_{2} \mathrm{H}_{2} \rightarrow \mathrm{S} 1-\mathrm{CS} 5$ is lower than that of $\mathrm{S} 1-\mathrm{CS} 1+\mathrm{C}_{2} \mathrm{H}_{2} \rightarrow \mathrm{S} 1-\mathrm{CS} 2$ by $8.7 \mathrm{kcal} / \mathrm{mol}$. This may be due to the enhanced reactivity at the edge of larger PAHs [14]. The corresponding IRC results are presented in Fig. S2 in the supplementary material.

Generally, characteristics of the bridge reaction system (S2) and the armchair reaction system (S1) are similar. The PES results indicate that the structures with the benzene ring in a staggered arrangement (S2-CS6) are more likely to be formed than those in a partially linear arrangement (S2-CS8), due to the lower energy barrier of the $\mathrm{C}_{2} \mathrm{H}_{2}$ addition reaction. This makes it easier for the PAHs$\mathrm{C}_{2} \mathrm{H}_{2}$ pathway to occur, as the vanishing of the bridge surface site gives more accessibility to the armchair surface site.

In order to more accurately estimate the energy barriers associated with the various reactions, the PES of naphthalene $+\mathrm{C}_{2} \mathrm{H}_{2}$ and $\mathrm{S} 2-\mathrm{CS} 1+\mathrm{C}_{2} \mathrm{H}_{2}$ reactions are refined at the CBS-QB3 level. Results show that the DFT method overestimates the energy barrier of the addition reaction of $\mathrm{C}_{2} \mathrm{H}_{2}$ to naphthalene by 6.9 and to S2-CS1 by $7.1 \mathrm{kcal} / \mathrm{mol}$ respectively, as illustrated in Figs.S3-S4. In the following kinetic analysis, the gaps in energy barriers calculated by DFT and CBS-QBS methods for other $\mathrm{C}_{2} \mathrm{H}_{2}$ addition reactions are assumed to 
Table 1

Reaction Rate Coefficients in the Form of $\mathrm{AT}^{\mathrm{n}} \exp (-\mathrm{E} / \mathrm{RT})^{\mathrm{a}}$.

\begin{tabular}{llll}
\hline Reaction & $A$ & $n$ & $E$ \\
\hline Armchair & & & \\
\hline $\mathrm{S} 1-\mathrm{CS} 1+\mathrm{C}_{2} \mathrm{H}_{2} \rightarrow \mathrm{S} 1-\mathrm{CS} 2$ & $2.1 \times 10^{2}$ & 2.585 & 39.92 \\
$\mathrm{~S} 1-\mathrm{CS} 2 \rightarrow \mathrm{S} 1-\mathrm{CS} 1+\mathrm{C}_{2} \mathrm{H}_{2}$ & $8.7 \times 10^{32}$ & -5.5 & 44.06 \\
$\mathrm{~S} 1-\mathrm{CS} 2 \rightarrow \mathrm{S} 1-\mathrm{CS} 3+\mathrm{H}_{2}$ & $1.3 \times 10^{10}$ & 0.7003 & 14.00 \\
$\mathrm{~S} 1-\mathrm{CS} 3+\mathrm{H}_{2} \rightarrow \mathrm{S} 1-\mathrm{CS} 2$ & $2.8 \times 10^{-3}$ & 4.27 & 70.36 \\
$\mathrm{~S} 1-\mathrm{CS} 4+\mathrm{C}_{2} \mathrm{H}_{2} \rightarrow \mathrm{S} 1-\mathrm{CS} 5$ & $4.6 \times 10^{1}$ & 2.603 & 31.18 \\
$\mathrm{~S} 1-\mathrm{CS} 5 \rightarrow \mathrm{S} 1-\mathrm{CS} 4+\mathrm{C}_{2} \mathrm{H}_{2}$ & $4.9 \times 10^{31}$ & -4.881 & 54.28 \\
$\mathrm{~S} 1-\mathrm{CS} 5 \rightarrow \mathrm{S} 1-\mathrm{CS} 6+\mathrm{H}_{2}$ & $3.4 \times 10^{12}$ & 0 & 22.26 \\
$\mathrm{~S} 1-\mathrm{CS} 6+\mathrm{H}_{2} \rightarrow \mathrm{S} 1-\mathrm{CS} 5$ & $6.4 \times 10^{2}$ & 2.363 & 66.14 \\
$\mathrm{Bridge}$ & & & \\
$\mathrm{S} 2-\mathrm{CS} 1+\mathrm{C}_{2} \mathrm{H}_{2} \rightarrow \mathrm{S} 2-\mathrm{CS} 2$ & $2.0 \times 10^{2}$ & 2.646 & 40.04 \\
$\mathrm{~S} 2-\mathrm{CS} 2 \rightarrow \mathrm{S} 2-\mathrm{CS} 1+\mathrm{C}_{2} \mathrm{H}_{2}$ & $3.9 \times 10^{-4}$ & 4.903 & 25.96 \\
$\mathrm{~S} 2-\mathrm{CS} 2 \rightarrow \mathrm{S}_{2}-\mathrm{CS} 3+\mathrm{H}_{2}$ & $1.2 \times 10^{12}$ & 0.1182 & 17.06 \\
$\mathrm{~S} 2-\mathrm{CS} 3+\mathrm{H}_{2} \rightarrow \mathrm{S} 2-\mathrm{CS} 2$ & $2.2 \times 10^{2}$ & 2.818 & 70.34 \\
$\mathrm{~S} 2-\mathrm{CS} 4+\mathrm{C}_{2} \mathrm{H}_{2} \rightarrow \mathrm{S} 2-\mathrm{CS} 5$ & $5.3 \times 10^{1}$ & 2.628 & 35.86 \\
$\mathrm{~S} 2-\mathrm{CS} 5 \rightarrow \mathrm{S} 2-\mathrm{CS} 4+\mathrm{C}_{2} \mathrm{H}_{2}$ & $3.5 \times 10^{6}$ & 2.174 & 33.74 \\
$\mathrm{~S} 2-\mathrm{CS} 5 \rightarrow \mathrm{S} 2-\mathrm{CS} 6+\mathrm{H}_{2}$ & $5.3 \times 10^{10}$ & 0.5964 & 19.20 \\
S2-CS6 $+\mathrm{H}_{2} \rightarrow \mathrm{S} 2-\mathrm{CS} 5$ & $5.8 \times 10^{1}$ & 2.826 & 64.80 \\
\hline
\end{tabular}

a The energy barrier of $\mathrm{C}_{2} \mathrm{H}_{2}$ addition reaction are estimated at CBS-QB3 level, and units are $\mathrm{kcal} / \mathrm{mol}, \mathrm{K}$, $\mathrm{cm}^{3} \mathrm{~mol}^{-1} \mathrm{~s}^{-1}$, and/s. The effective temperature ranges from 800 to $2500 \mathrm{~K}$, and the pressure is $1 \mathrm{~atm}$.

be the same as for the $\mathrm{S} 2-\mathrm{CS} 1+\mathrm{C}_{2} \mathrm{H}_{2}$ (naphthalene $+\mathrm{C}_{2} \mathrm{H}_{2}$ ) reaction; this is because the $\mathrm{C}_{2} \mathrm{H}_{2}$ addition reactions on larger PAHs present almost similar reaction features, including the vibration mode of transition state and the energy barrier at B3LYP $6-311+\mathrm{G}(\mathrm{d}, \mathrm{p})$ level.

\subsection{Kinetic analysis}

The rate coefficients are evaluated at $1 \mathrm{~atm}$ and for a temperature range of $800-2500 \mathrm{~K}$. To examine the accuracy of our rate coefficients, the theoretical rate coefficients of phenoxy decomposition and $\mathrm{C}_{6} \mathrm{H}_{5}+\mathrm{C}_{2} \mathrm{H}_{2} \rightarrow \mathrm{C}_{6} \mathrm{H}_{5} \mathrm{C}_{2} \mathrm{H}+\mathrm{H}$ addition reactions were compared with corresponding experimental values in previous studies [5,17], and the uncertainty is within a factor of 3 . Additionally, our rate coefficient calculation results for the reaction of $\mathrm{S} 2-\mathrm{CS} 1+\mathrm{C}_{2} \mathrm{H}_{2} \rightarrow \mathrm{S} 2-\mathrm{CS} 2$ are compared with those reported by Kislov et al. [16]. The values reported here are slower by a factor of 1.27 at $1500 \mathrm{~K}$. The details and deviation analyses are provided in Tables $\mathrm{S} 1-\mathrm{S} 2$. The formation of $\mathrm{S} 2-\mathrm{CS} 8$ species with partial benzene rings in a linear arrangement in the $\mathrm{S} 2$ reaction system is not considered here due to their higher energy barriers compared with the energy barriers for the formation of S2-CS6. The kinetic parameters of the PAHs- $\mathrm{C}_{2} \mathrm{H}_{2}$ reactions are presented in Table 1.

As shown in Fig. 2(a), the values of the rate coefficients for the $\mathrm{C}_{2} \mathrm{H}_{2}$ addition reaction on zig-zag (S3-CS1) and 5-membered ring surface sites (S4-
CS1) are quite close, but much lower than those for the armchair (S1-CS1) and bridge surface sites (S2-CS1). This means that the new carbon ring is more likely to be formed on the armchair or bridge surface site of PAHs and soot surface. We also observed that the rate coefficients of $\mathrm{C}_{2} \mathrm{H}_{2}$ additions to PAHs are at least 5 orders of magnitude lower than those for $\mathrm{C}_{2} \mathrm{H}_{2}$ additions to PAHs radical even at $1500 \mathrm{~K}$ due the higher energy barrier. The comparisons between the reaction rate coefficients of $1-\mathrm{H}$ and $2-\mathrm{H}$ elimination reactions indicate that more attention should be given to $2-\mathrm{H}$ elimination reactions, as shown in Fig. 2(b). The energy barrier of $2-\mathrm{H}$ elimination reaction varies from 14.0 to $85.0 \mathrm{kcal} / \mathrm{mol}$ in this study, its correlation with PAHs structure is shown in Fig. 3. It seems that the structure symmetry along the two $\mathrm{C}$ atoms where the redundant $\mathrm{H}$ atom locates is the main factor determining the energy barrier of 2$\mathrm{H}$ elimination reaction. If the molecule structure is symmetrical like (a) and (b) in Fig. 3, the 2-H elimination is easy to happen with a lower energy barrier $(14.8$ and $14.2 \mathrm{kcal} / \mathrm{mol})$. The energy barrier increases to $20.4 \mathrm{kcal} / \mathrm{mol}$ if the whole structure like (c) in Fig. 3 is asymmetrical along the purple dash line, but the local structure is symmetrical (both $\mathrm{C}$ atoms connect to two benzene rings). If the local structure is asymmetrical like (d) in Fig. 3, where one $\mathrm{C}$ atom connects two 5-membered rings and the other $\mathrm{C}$ atom connects 5-membered ring and benzene ring, the $2-\mathrm{H}$ elimination reaction is unlikely to happen due to the relative high energy barrier $(85.0 \mathrm{kcal} / \mathrm{mol})$.

\subsection{Simulation for pyrene formation}

Here, we discuss the competitiveness of the proposed PAHs- $\mathrm{C}_{2} \mathrm{H}_{2} \quad\left(\mathrm{PAHs}+\mathrm{C}_{2} \mathrm{H}_{2} \rightarrow\right.$ intermediate $\rightarrow$ product $+\mathrm{H}_{2}$ ) pathway relative to the $\mathrm{HACA}(\mathrm{PAHs}+\mathrm{H} \rightarrow \mathrm{PAHs}$ radical $\left(+\mathrm{C}_{2} \mathrm{H}_{2}\right) \rightarrow$ intermediate $\rightarrow$ product $\left.+\mathrm{H}\right)$ pathway. To this end, the formation of pyrene starting from phenanthrene in a closed homogeneous zero-dimensional reactor is simulated, using the Chemkin Pro software. For convenience, phenanthrene is also considered as a part of the soot $\left(\mathrm{C}_{\mathrm{n}} \mathrm{H}_{\mathrm{m}}\right)$ surface and pyrene as the addition product $\left(\mathrm{C}_{\mathrm{n}+2} \mathrm{H}_{\mathrm{m}}\right)$ in the rate discussion of soot surface growth. These assumptions are reasonable as the reaction type and reaction rate constant of the soot surface growth are considered to be equal to that of PAHs surface growth along the HACA pathway in current soot models [7,27]. The rate constants of soot surface growth on an armchair surface site via the PAHs- $\mathrm{C}_{2} \mathrm{H}_{2}$ pathway are assumed to be equal to that of $\mathrm{S} 1-\mathrm{CS} 4-\mathrm{C}_{2} \mathrm{H}_{2}$ due to its size. To make the comparison more rigorous, $\mathrm{H}$ abstraction from every $\mathrm{C}$ atom on phenanthrene surface is considered as shown in Fig. S5 [28]. The addition reactions of $\mathrm{H}$ and $\mathrm{O}_{2}$ with $\mathrm{PAH}$ radicals (soot radicals) are also considered for 


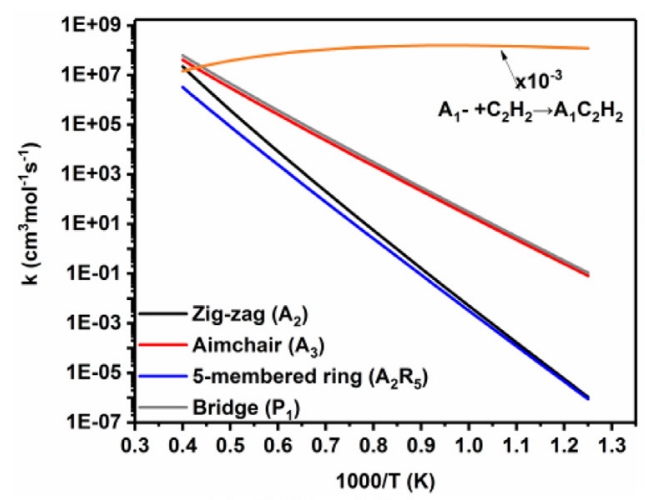

(a) $\mathrm{C}_{2} \mathrm{H}_{2}$ addition

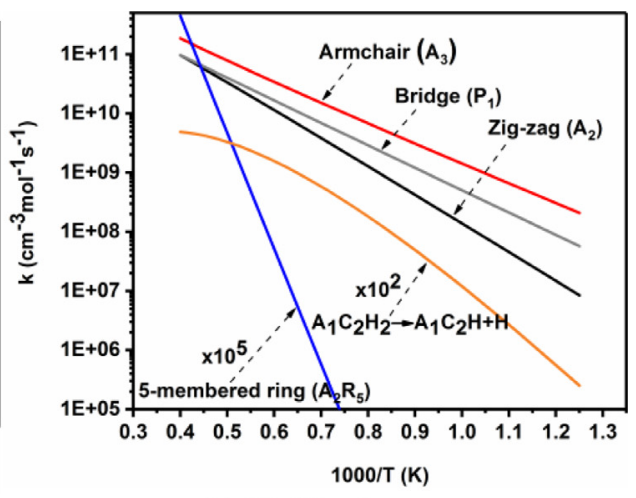

(b) $\mathrm{H}_{2} / \mathrm{H}$ release

Fig. 2. Comparisons of reaction rates for the PAHs $+\mathrm{C}_{2} \mathrm{H}_{2}$ pathway, the rate coefficients of $\mathrm{A}_{1}-+\mathrm{C}_{2} \mathrm{H}_{2} \rightarrow \mathrm{A}_{1} \mathrm{C}_{2} \mathrm{H}_{2}$ and $\mathrm{A}_{1} \mathrm{C}_{2} \mathrm{H}_{2} \rightarrow \mathrm{A}_{1} \mathrm{C}_{2} \mathrm{H}+\mathrm{H}$ come from [26].

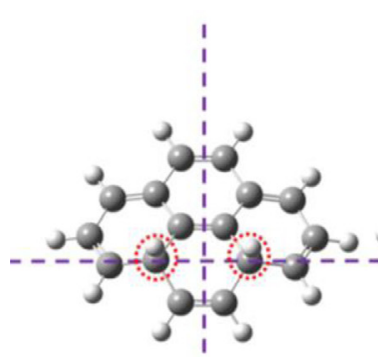

$14.8 \mathrm{kcal} / \mathrm{mol}$

(a)

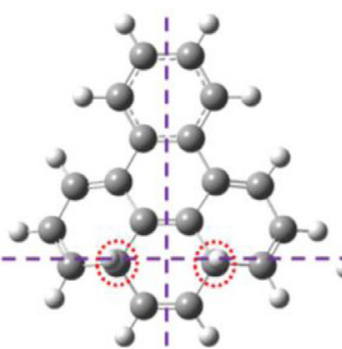

$14.2 \mathrm{kcal} / \mathrm{mol}$

(b)

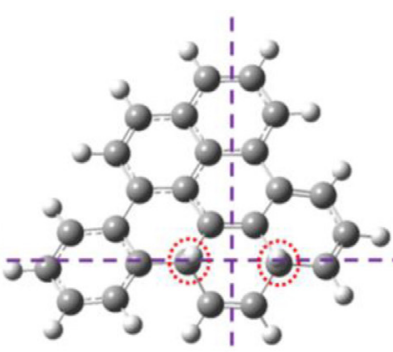

$20.4 \mathrm{kcal} / \mathrm{mol}$

(c)

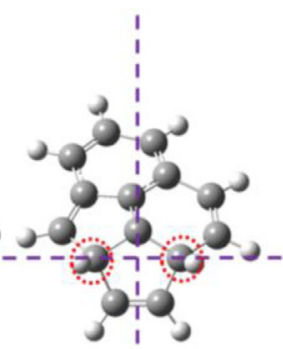

$85.0 \mathrm{kcal} / \mathrm{mol}$

(d)

Fig. 3. The correlation of PAHs structure with the energy barrier of 2-H elimination reaction.

the HACA pathway, as the active site on PAHs (soot) is available for $\mathrm{H}$ and $\mathrm{O}_{2}$ before being targeted by $\mathrm{C}_{2} \mathrm{H}_{2}[28,29]$. The specific reactions and corresponding reaction rate coefficients used in the simulation of PAHs and soot surface growth along HACA pathway are listed in Table S4 and Table S5 respectively. The species considered in the simplified combustion atmosphere include phenanthrene, $\mathrm{C}_{2} \mathrm{H}_{2}, \mathrm{O}_{2}, \mathrm{H}_{2}, \mathrm{H}$, and $\mathrm{N}_{2}$. The mole fractions of phenanthrene, $\mathrm{C}_{2} \mathrm{H}_{2}, \mathrm{O}_{2}$, and $\mathrm{H}_{2}$ are fixed at $0.0001,0.04,0.15,0.1$, in accordance with the experimental results [30-32]. Temperature and mole fraction of $\mathrm{H}$ (mole fraction of $\mathrm{N}_{2}=1-$ others) are abstracted at different heights above burner surface (HABs) in the premixed stagnation flame at $\mathrm{C}_{2} \mathrm{H}_{4} / \mathrm{O}_{2} / \mathrm{Ar}=16.15 / 23.44 / 60.41$ with a inlet gas velocity of $20 \mathrm{~cm} / \mathrm{s}$, using the $\mathrm{ABF}$ mechanism [7]. The simulation is carried out at 1 atm with a residence time of $0.02 \mathrm{~s}$.

The formation of pyrene was investigated at different $\mathrm{HABs}$ where the peak concentration of $\mathrm{H}$ atom $\left(\mathrm{A}, \mathrm{T}=1575 \mathrm{~K}, \mathrm{H}=7.17 \times 10^{-4}\right)$, the peak flame temperature $(\mathrm{B}, \mathrm{T}=1839 \mathrm{~K}$, $\left.\mathrm{H}=2.10 \times 10^{-4}\right)$, and the turning point of temperature profile $\left(\mathrm{C}, \mathrm{T}=1672 \mathrm{~K}, \mathrm{H}=4.89 \times 10^{-5}\right)$ are located and shown in Fig. 4(a). During the growth of PAHs, pyrene is predominantly formed with the HACA pathway in the main reaction zone (A), mainly formed through the $\mathrm{S} 1-\mathrm{CS} 1-\mathrm{C}_{2} \mathrm{H}_{2}$ pathway at position B and C, as shown in Fig. 4(b). Comparative results also indicate that the pyrene formation is mainly constrained by the $\mathrm{H}$ mole fraction for HACA pathway, and by the flame temperature for the PAHs- $\mathrm{C}_{2} \mathrm{H}_{2}$ pathway.

Observations show that soot surface growth on armchair surface sites by $\mathrm{PAHs}-\mathrm{C}_{2} \mathrm{H}_{2}$ pathway is competitive with that of HACA pathway in the past-flame region (Fig. 4(b)). We also investigate the formation of acenaphthylene (S3-CS3) starting from naphthalene (S3-CS1), either with a HACA or a naphthalene $+\mathrm{C}_{2} \mathrm{H}_{2} \rightarrow$ acenaphthylene $+\mathrm{H}_{2}$ pathway. Results show that the latter pathway is unable to compete with the HACA pathway, even in the post-flame region of high-temperature flame. 


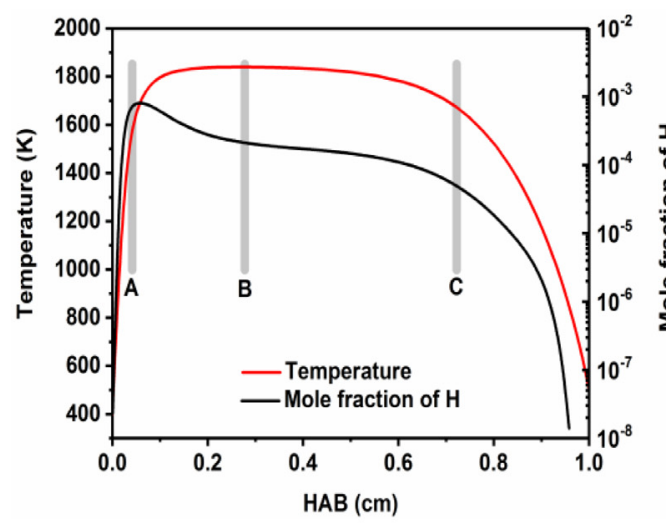

(a)

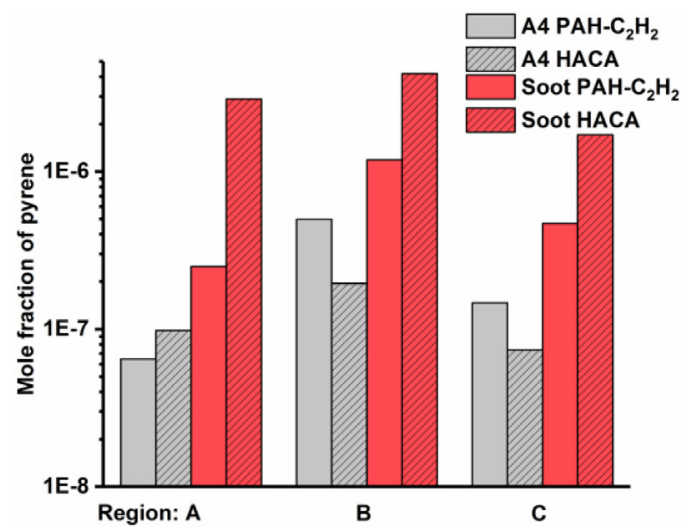

(b)

Fig. 4. The mole fractions of $\mathrm{H}$, temperature in premixed stagnation flames at $\mathrm{C}_{2} \mathrm{H}_{4} / \mathrm{O}_{2} / \mathrm{Ar}=16.15 / 23.44 / 60.41$, $V_{\text {cold-gas }}=20 \mathrm{~cm} / \mathrm{s}(\mathrm{a})$, and mole fraction of pyrene in $0-\mathrm{D}$ chamber at $\mathrm{t}=0.02 \mathrm{~s}(\mathrm{~b})$.

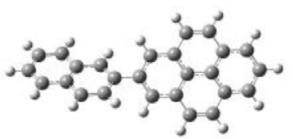

(a)

Main-flame region

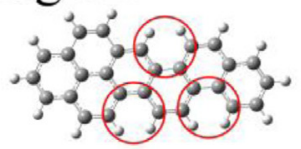

(d)

Post-flame region

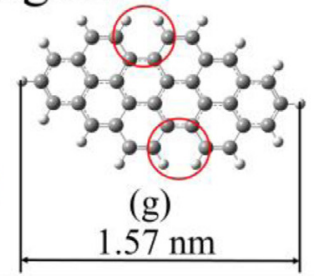

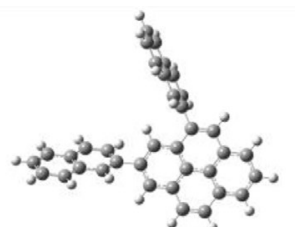

(b)

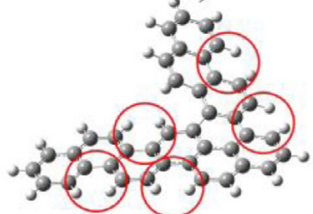

(e),

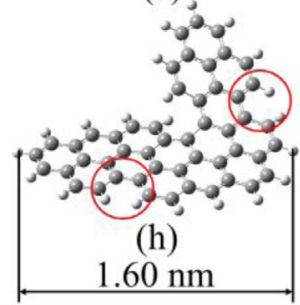

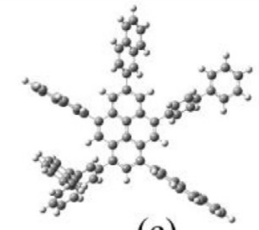

(c)

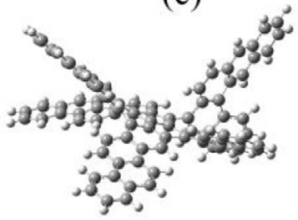

(f)

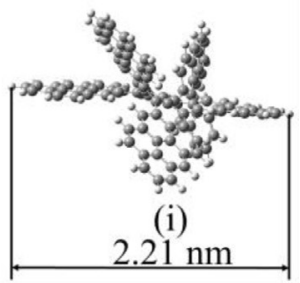

Fig. 5. Conceptual mechanism of soot nucleation and surface growth, with structures optimized at pm6 level.

\subsection{Implications for soot nucleation and surface growth}

Currently, there are three conceptual pathways leading to soot nucleation [3,33-36]: 1) the dimerization of two pyrene molecules [36], 2) the formation of fullerene-like structures from large PAHs via a HACA pathway [33], 3) the chemical coalescence of moderate-sized PAHs into crosslinked three-dimensional structures via the addition reaction of PAHs and PAH radicals [37,38] as shown in Fig. 5(a)-(c). However, each pathway has a concern. In the first pathway, the dimer is likely to be dissociated at flame temperatures due to the weak binding energy [39] and the non-reactive collisions with gas molecules [3]. The rate of the second pathway is too low to capture the experimentally determined soot nucleation rates in flames [40]. The third pathway is limited to the generation of PAH radicals via $\mathrm{H}$-abstraction reaction and possible further growth in the post-flame region where $\mathrm{H}$ atoms are rare. By investigating $\mathrm{PAHs}-\mathrm{C}_{2} \mathrm{H}_{2}$ pathway, we 
hope to dispel this doubt. One can easily speculate that $\mathrm{C}_{2} \mathrm{H}_{2}$ will bond to two PAH fragments connected by the bridge surface site on the crosslinked three-dimensional structure, similarly to the process (a) $\rightarrow$ (d), (b) $\rightarrow$ (e), and (c) $\rightarrow$ (f) shown in Fig. 5. The termination of one bridge site gives birth to two or three armchair sites, which is illustrated by the processes (a) $\rightarrow$ (d) and (b) $\rightarrow$ (e). Furthermore, a new armchair site can also be formed when the existing armchair site is occupied, which is evidenced by the processes $(\mathrm{d}) \rightarrow(\mathrm{g})$ and $(\mathrm{e}) \rightarrow(\mathrm{h})$. In this way, the thermal stability of the curved three-dimensional structure is enhanced by bridging two PAH fragments, and the formed structure then rapidly grows up in the main-flame and postflame region via the addition of $\mathrm{C}_{2} \mathrm{H}_{2}$ on the newly formed armchair site, as shown in Fig. 5.

\section{Conclusion}

In this study, the PAHs- $\mathrm{C}_{2} \mathrm{H}_{2}$ reaction mechanism is investigated by applying both DFT B3LYP 6-311 + G(d,p) and RRKM theories. Also, the formation of pyrene under sooting conditions for both the HACA and the PAHs- $\mathrm{C}_{2} \mathrm{H}_{2}$ pathways is studied using a zero-D reactor. Additionally, the nucleation and surface growth of soot with the PAHs- $\mathrm{C}_{2} \mathrm{H}_{2}$ pathway are discussed.

Apart from HACA pathway, our results show that the growth of PAHs and soot can be achieved by a $\mathrm{C}_{2} \mathrm{H}_{2}$ addition followed by an $\mathrm{H}_{2}$ releasing reaction. In some reactions, the energy barrier of a simultaneous elimination of $2-\mathrm{H}(14-23.8 \mathrm{kcal} / \mathrm{mol})$ is much lower than that of $1-\mathrm{H}$ elimination reaction (typically $30-40 \mathrm{kcal} / \mathrm{mol}$ ).

Potential energy surface and kinetic analysis indicate that the armchair and bridge surface sites are inclined to be occupied by $\mathrm{C}_{2} \mathrm{H}_{2}$ molecules compared with the zig-zag and 5-membered ring.

The simulation of pyrene formation suggest that the HACA pathway is dominant in the main-flame region where $\mathrm{H}$ atoms are abundant, and the PAHs$\mathrm{C}_{2} \mathrm{H}_{2}$ pathway occurring on armchair and bridge surface sites is more competitive in the post-flame region where $\mathrm{H}$ atoms are rare, especially in hightemperature flames.

The soot nucleation is likely initiated by the chemical coalescence of moderate-sized PAHs into crosslinked three-dimensional structures via the addition reaction of PAH and PAH radicals in the main-flame region, followed by the addition of $\mathrm{C}_{2} \mathrm{H}_{2}$ on the bridge and armchair sites of soot surface in the post-flame region.

\section{Acknowledgment}

The research reported in this publication was supported by the Clean Combustion Research Cen- ter at the King Abdullah University of Science and Technology (KAUST).

\section{Supplementary materials}

Supplementary material associated with this article can be found, in the online version, at doi: 10.1016/j.proci.2018.05.047.

\section{References}

[1] Y.Z. An, Y.Q. Pei, J. Qin, et al., Energy 94 (2016) 367-379.

[2] Y.Z. An, M. Jaasim, R. Vallinayagam, S. Vedharaj, H.G. Im, B. Johansson, Fuel 211 (2018) 420-431.

[3] H. Wang, Proc. Combust. Inst. 33 (2011) 41-67.

[4] Y.Z. An, X. Li, S.P. Teng, et al., Fuel 179 (2016) 246-257.

[5] P. Liu, H. Lin, Y. Yang, C. Shao, B. Guan, Z. Huang, J. Phys. Chem. A 119 (2015) 3261-3268.

[6] H. Lin, P. Liu, Z. He, Y. Zhang, B. Guan, Z. Huang, Int. J. Hydrogen Energy 41 (2016) 13736-13746.

[7] M. Frenklach, Phys. Chem. Chem. Phys. 4 (2002) 2028-2037.

[8] P. Liu, H. Lin, Z. He, Y. Zhang, B. Guan, Z. Huang, Int. J. Hydrogen Energy 41 (2016) 3249-3258.

[9] M. Frenklach, H. Wang, Proc. Combust. Inst. 23 (1991) 1559-1566

[10] J.C. Meyer, A.K. Geim, M.I. Katsnelson, K.S. Novoselov, T.J. Booth, S. Roth, Nature 446 (2007) 60-63.

[11] P. Liu, Z. He, G.-L. Hou, B. Guan, H. Lin, Z. Huang, J. Phys. Chem. A 119 (2015) 13009-13017.

[12] M. Ezawa, Phys. Rev. B 76 (2007) 245415.

[13] K.S. Novoselov, Z. Jiang, Y. Zhang, et al., Science 315 (2007) 1379

[14] H. Nagai, M. Nakano, K. Yoneda, et al., Chem. Phys. Lett. 489 (2010) 212-218.

[15] H.B. Zhang, D. Hou, C.K. Law, X. You, J. Phys. Chem. A 120 (2016) 683-689.

[16] V. Kislov, A. Mebel, S. Lin, J. Phys. Chem. A 106 (2002) 6171-6182

[17] P. Liu, H. Lin, Y. Yang, C. Shao, C. Gu, Z. Huang, J. Phys. Chem. A 118 (2014) 11337-11345.

[18] X. You, H. Wang, H.B. Zhang, M.J. Pilling, Phys. Chem. Chem. Phys. 18 (2016) 12149-12162.

[19] B. Shukla, M. Koshi, Phys. Chem. Chem. Phys. 12 (2010) 2427-2437

[20] A.D. Becke, J. Chem. Phys. 96 (1992) 2155-2160.

[21] C. Lee, W. Yang, R.G. Parr, Phys. Rev. B 37 (1988) 785.

[22] M.J. Frisch, G.W. Trucks, H.B. Schlegel, G.E. Scuseria, M.A. Robb, J.R. Cheeseman, et al., GAUSSIAN 09, Revision D.01, Gaussian, Inc., Wallingford CT, 2013.

[23] J.R. Barker, N.F. Ortiz, J.M. Preses, et al., MultiWell-2016.2, University of Michigan, Ann Arbor, MI, 2016.

[24] J.R. Barker, Int. J. Chem. Kinet. 41 (2009) 748-763.

[25] J.R. Barker, Int. J. Chem. Kinet. 33 (2001) 232-245.

[26] H. Wang, M. Frenklach, J. Phys. Chem. 98 (1994) 11465-11489.

[27] A.M. Mebel, Y. Georgievskii, A.W. Jasper, S.J. Klippenstein, Proc. Combust. Inst. 36 (2017) 919-926. 
[28] A. Semenikhin, A. Savchenkova, I. Chechet, et al., Phys. Chem. Chem. Phys. 19 (2017) 25401-25413.

[29] M. Frenklach, Z. Liu, R.I. Singh, G.R. Galimova, V.N. Azyazov, A.M. Mebel, Combust. Flame 188 (2018) 284-306.

[30] S. Sinha, A. Raj, Phys. Chem. Chem. Phys. 18 (2016) $8120-8131$

[31] M.J. Castaldi, N.M. Marinov, C.F. Melius, et al., Proc. Combust. Inst. 26 (1996) 693-702.

[32] E. Georganta, R.K. Rahman, A. Raj, S. Sinha, Combust. Flame 185 (2017) 129-141.

[33] K.H. Homann, Angew. Chem. Int. Edit. 37 (1998) $2434-2451$

[34] J.D. Herdman, J.H. Miller, J. Phys. Chem. A 112 (2008) 6249-6256.
[35] S.H. Chung, A. Violi, J. Chem. Phys. 132 (2010) 174502.

[36] C.A. Schuetz, M. Frenklach, Proc. Combust. Inst. 29 (2002) 2307-2314.

[37] A. Violi, A.F. Sarofim, G.A. Voth, Combust. Sci. Technol. 176 (2004) 991-1005.

[38] A. Violi, A. Kubota, T.N. Truong, W.J. Pitz, C.K. Westbrook, A.F. Sarofim, Proc. Combust. Inst. 29 (2002) 2343-2349.

[39] H. Sabbah, L. Biennier, S.J. Klippenstein, I.R. Sims, B.R. Rowe, J. Phys. Chem. Lett. 1 (2010) 2962-2967.

[40] S.J. Harris, A.M. Weiner, C. Cleveland Ashcraft, Combust. Flame 64 (1986) 65-81. 